\title{
DETERMINATION OF THE PRINCIPAL STRESSES OF A SNOW COVER ON A MOUNTAIN SLOPE USING SNOW PRESSURE GAUGES
}

\author{
by
}

\author{
Mitsuo OH'tzumi and Tosio Huzioka
}

Institute of Low Temperature Science, Hokkaido University, Sapporo, Japan 060

\begin{abstract}
Principal stresses in a snow cover on a uniform slope were determined by two methods, each using thin pressure gauges to measure snow pressure in the snow. These snow pressures were principal stress $\sigma_{2}$ on a vertical plane perpendicular to the contour lines and normal compressive stress $\sigma_{\theta}$ on a plane perpendicular to the vertical plane. In addition, plastic Poisson's ratio $v$ was estimated in a snow cover on level ground. Estimates of principal strain rates were used to calculate principal stresses and viscosity by two different methods, using estimates of $v$ and the constitutive equations of Yosida (1980) and the derived values of $\sigma_{2}$ and $\sigma_{\theta}$. For dry and compact snow, $\sigma_{1}$ and $\sigma_{3}$ calculated by both methods agreed well with each other, and also with values obtained by the hole-mark method reported by Shimizu and Huzioka (1975).
\end{abstract}

\section{INTRODUCTION}

Snow cover flows down a uniform slope two-dimensionally along the steepest direction. On an assumption that a finite homogeneous strain takes place in each layer of the snow cover, Huzioka and others (1982) measured the principal strain rates of snow in each snow layer, and calculated the principal stresses by the hole-mark method (Shimizu and Huzioka 1975). This method cannot be applied, however, to snow cover in which layer boundaries are not parallel to the ground surface. In the present study the authors calculated principal stress $\sigma_{2}$, normal compressive stress $\sigma_{\theta}$ and plastic Poisson's ratio $v$, with data from thin snow pressure gauges.

\section{CONSTITUTIVE EQUATIONS}

Natural snow may be assumed to be isotropic and homogeneous in each layer of the snow cover, except when composed of depth hoar crystals or new snow. Then the directions of the principal axes of the stresses are in accordance with those of the strain rates. When internal stresses in each layer are constant or change very slowly in magnitude, like the snow cover on a slope, the snow behaves like a compressible viscous fluid with a large viscosity $\eta$ as well as plastic Poisson's ratio $v$ which is a measure of compressibility and a function of snow type, density and snow temperature (Yosida 1980). The equations are:

$$
\begin{aligned}
& \dot{\epsilon}_{1}=\left\{\sigma_{1}-v\left(\sigma_{2}+\sigma_{3}\right)\right\} /\{2 \eta(1+v)\}, \\
& \left.\dot{\epsilon}_{2}=\left\{\sigma_{2}-v\left(\sigma_{3}+\sigma_{1}\right)\right\} /\{2 \pi(1+v)\},\right\} \\
& \left.\dot{\epsilon}_{3}=\left\{\sigma_{3}-v\left(\sigma_{1}+\sigma_{2}\right)\right\} /\{2 \pi(1+v)\}_{1}\right\}
\end{aligned}
$$

where $\dot{\epsilon}_{i}$ and $\sigma_{i}(i=1,2,3)$ are positive in the case of extension and tensile stress, respectively; $\dot{\epsilon}_{1}>\dot{\epsilon}_{3}$ and $\sigma_{1}>\sigma_{3}$. We neglect the static pressure term in the equations, because there is no possibility for a state of rest to be reached in naturally deposited snow (Salm 1967).

\section{METHODS}

Now take both the vertical $z$-axis and the horizontal $x$-axis on a slope, and the $y$-axis parallel to the contour line. Due to the simple geometry, plane strain conditions are assumed. Because snow flows down two-dimensionally along the vertical plane (the $z-x$ plane), strain rate perpendicular to the $\mathrm{z}-\mathrm{x}$ plane, $\dot{\epsilon}_{\mathbf{y}}$, is zero in magnitude and equal to principal strain rate $\dot{\epsilon}_{2}(=0)$ Two other principal strain rates $\dot{\epsilon}_{1}, \dot{\epsilon}_{3}$ lie on the $z-x$ plane. For the principal strain rate in the direction of the y-axis $\dot{\epsilon}_{2}$ is used always, regardless of the relative magnitude of $\dot{\epsilon}_{1}$ or $\dot{\epsilon}_{3}$. The directions of principal stresses $\sigma_{1}, \sigma_{2}$ and $\sigma_{3}$ are assumed to coincide with those of $\dot{\epsilon}_{1}, \dot{\epsilon}_{2}$ and $\dot{\epsilon}_{3}$. So principal stress $\sigma_{2}$, which is mostly compressive, points to the direction of the y-axis.

\section{METHODS I AND II}

We obtained $\sigma_{2}$ and normal compressive stress $\sigma_{\theta}$ in a snow cover on a slope to calculate $\sigma_{1}$ and $\sigma_{3}$, using snow pressure gauges. The stress $\sigma_{\theta}$ was perpendicular to $\sigma_{2}$. If $v$ can be given in some way, unknown values $\sigma_{1}$, $\sigma_{3}$ and $\eta$ are calculated from Equation 1, using values $\sigma_{2}$, and measuring values of $\dot{\epsilon}_{1}$ and $\dot{\epsilon}_{3}$ (Method I). The latter two were to be obtained by the hole-mark method.

In addition to $\sigma_{2}, \dot{\epsilon}_{1}$ and $\dot{\epsilon}_{3}$, if $\sigma_{\theta}$ and $\theta$, the angle between the direction of $\sigma_{\theta}$ and the $x$-axis, can be obtained, then $\sigma_{1}, \sigma_{3}, \eta$ and $v$ are calculated from both Equation 1 and $\sigma_{\theta}=\sigma_{1} \cos ^{2}(\theta-\alpha)+\sigma_{3} \sin ^{2}(\theta-\alpha)$, where $\alpha$ is the angle between the direction of $\sigma_{1}$ and the $x$-axis (Method II). This pressure gauge can measure only a compressive stress. When setting up the gauge in the snow, if $\theta$ is taken near $90^{\circ}$, then $\sigma_{\theta}$ can be measured for a fairly long time. As $\dot{\epsilon}_{1}$ and $\dot{\epsilon}_{3}$ are mean values for about two weeks, the other values are also the averages for the same period.

\section{PLASTIC POISSON'S RATIO}

Plastic Poisson's ratio is defined as $-\dot{\epsilon}_{\mathrm{b}} / \dot{\epsilon}_{\mathrm{a}}$ under uniaxial stress, where $\dot{\boldsymbol{\epsilon}}_{\mathrm{a}}$ is axial strain rate and $\dot{\boldsymbol{\epsilon}}_{\mathrm{b}}$ strain rate of the radial direction. In the present study $v$ was obtained, based on equation 1 , from a snow cover on a level ground, where the vertical strain rate was $\dot{\boldsymbol{\epsilon}}_{3}$ and other two principal strain rates were on the horizontal plane. Let $\sigma_{3}$ be called vertical pressure $P_{v}$ and $\sigma_{1}\left(=\sigma_{2}\right)$ horizontal pressure $P_{h}$; then from both equation 1 and $\dot{\epsilon}_{1}=\dot{\epsilon}_{2}=0$, and from $P_{v}$ and $P_{h}$, using the following equation $v$ can be obtained:

$$
v=\sigma_{1} /\left(\sigma_{2}+\sigma_{3}\right)=P_{h} /\left(P_{h}+P_{v}\right) \text {. }
$$

\section{SNOW PRESSURE GAUGE}

The coefficient of pressure at rest, $P_{h} / P_{v}$, had been measured by de Quervain (1965). But this attempt was inaccurate because the pressure gauge was so thick that snow flow was disturbed. This prompted the authors to construct a thin pressure gauge. 


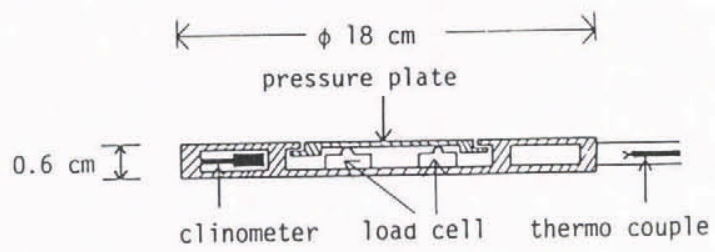

Fig.1. Cross-section of the snow pressure gauge.

The snow pressure gauge (Figure 1) was a disk 0.6 $\mathrm{cm}$ thick, $18 \mathrm{~cm}$ in diameter and $285 \mathrm{~g}$ in weight (Shimizu and others 1985). Snow pressure on a pressure plate $9 \mathrm{~cm}$ in diameter is transmitted to three load cells of small size in the gauge. A clinometer is set inside the gauge to measure $\theta$. The clinometer is a cantilever which has two strain gauges attached on each side. Output from the clinometer changes sinusoidally as the normal of the pressure plate changes from horizontal to vertical. A thermo-couple is put into the snow to measure snow temperature. Drift due to temperature change is $\pm 1.96 \mathrm{~Pa} /{ }^{\circ} \mathrm{C}$ from the load cells, and \pm 0.31 degree $/{ }^{\circ} \mathrm{C}$ from the clinometer.

\section{RESULTS AND DISCUSSION}

Plastic Poisson's ratio $\mathrm{v}$ in snow cover on level ground

Plastic Poisson's ratio $v$ was calculated from measurements in snow cover on level ground at Toikanbetsu, northern Hokkaido, in winter of 1983. Snow pressure gauges were set in a unit snow layer at a distance of $60 \mathrm{~cm}$ from a vertical snow wall, together with a setting instrument. In this way inclinations of the gauge of less than $2^{\circ}$ was possible throughout the measuring periods, maintaining high reliability. Measurements from the gauges were recorded every 3 hours.

On 19 January 1983 two pairs of gauges, A and B were inserted into a snow layer at the same level and 6 $m$ apart, in each pair one measured $P_{v}$ and the other $P_{h}$. The normal of the pressure plate measuring $P_{v}$ was pointed vertically, that for $P_{h}$ horizontally. Pair $A^{v}$ were dug out on 2 February and their state in the snow layer was checked; then they were buried again slightly higher than before in the same layer.

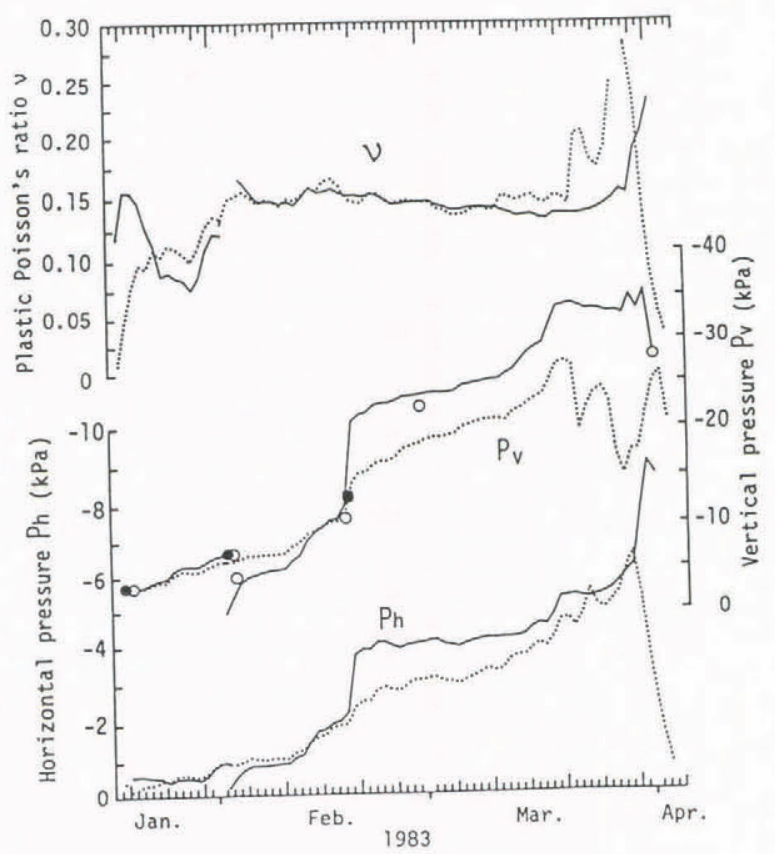

Fig.2. Vertical pressure $P_{y}$, horizontal pressure $P_{h}$ and plastic Poisson's ratio v. Solid lines : A; dotted lines : B. Water equivalent above the gauge - $\mathrm{O}$ : for gauge $\mathrm{A}$; for gauge $\mathrm{B}$.
Figure 2 shows vertical pressure $P_{v}$, horizontal pressure $\mathrm{P}_{h}$ and plastic Poisson's ratio $v$; values of pair $A$ are shown by solid lines and those of $B$ by dotted lines. Water equivalents above the gauge are also shown in Figure 2. The negative sign in the ordinate in Figures 2 and 3 means the stress is compressive (pressure). As for water equivalents above the gauge, those at $A$ are marked by blank circles, and those at B by solid circles. The vertical pressure in A or B almost agrees each with the water equivalent above the gauge. Because the inclinations of all gauges were small, magnitudes of corrections for $P_{v}$ or $P_{h}$ were negligibly small.

The increment of $P_{y}$ in $A$ differed from that in $B$ on 13 and 18 February because snowstorms on both days precipitated new snow with different water equivalents, affected by a building near the site. Large fluctuation of $P_{V}$ in $B$ in late March was due to poor contact of the gauge to the surrounding snow on account of meltwater.

The general tendency of horizontal pressure $\mathrm{P}_{h}$ is the same as that of $P_{v}$; for example, a rise in $A$ on 18 February and a large fluctuation in $\mathbf{B}$ in the last ten days of March. There is nothing that identifies the real horizontal pressure, like the water equivalent in the case of vertical pressure. Judging from the fact that $P_{h}$ in $A$ agreed with or is parallel to $p_{h}$ in $B$, and snow around the gauge was scarcely affected by the gauge, measured values in $P_{h}$ seem to be reliable too.

It is remarkable that there was no rise in plastic Poisson's ratio $v$ at A on 18 February, corresponding to that of $P_{y}$ or $P_{h}$. It can be understood that $P_{h}$ also increases so rapidly as to make $v$ constant whenever $P_{v}$ increases rapidly. From 15 February to 15 March, when $v$ is almost constant, the mean valueof $v$ of $A$ or $B$ was 0.15 for a dry and compact snow, when density changed from 280 to $380 \mathrm{~kg} / \mathrm{m}^{3}$ and temperature ranged from -4 to $-1{ }^{\circ} \mathrm{C}$. This result that $\bar{v}=0.15$ for a compact snow agrees with $v$ in the preliminary measured value from the gauges set in the same way as this time. Plastic Poisson's ratio appears to be little affected by snow temperature above $-4^{\circ} \mathrm{C}$.

Principal stresses $\sigma_{1}$ and $\sigma_{3}$ in snow cover on a slope.

Lateral pressure $\sigma_{2}$ and normal compressive stress $\sigma_{\theta}$

The authors measured lateral pressure (2nd principal stress) $\sigma_{2}$ as well as normal compressive stress $\sigma_{\theta}$ in a snow cover on a north-facing slope at Toikanbetsu. Slope inclination was $32^{\circ}$. Period of measurement was from 1 February to 29 March. Snow pressure, snow temperature and inclination of the gauge were measured every hour. The gauge was set into the snow in the same way as on the level ground. The strain rate was measured in the snow near the site.

Figure 3 shows $\sigma_{2}$ and $\sigma_{\theta}$. Dotted lines in Figure 3 represent the portions lacking data due to the recorder's error. Angles between the $y$-axis and the normal of the pressure plate of the gauge for $\sigma_{2}$ were almost $0^{\circ}$ through all the measurement periods. When two gauges were dug out, contacts between the gauges and the snow were found to be fairly good and the normal of the

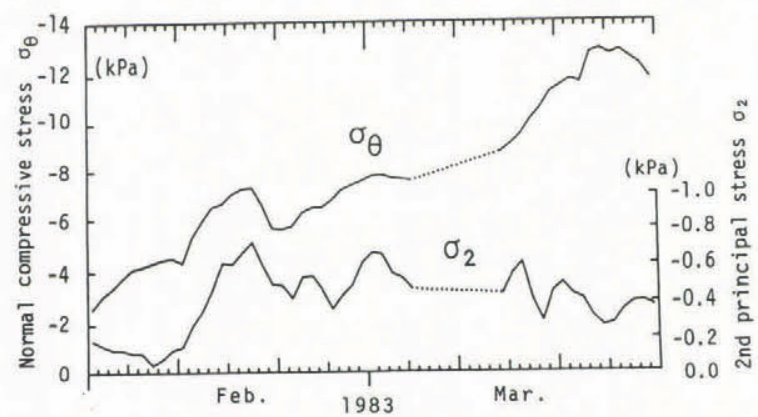

Fig.3. Lateral pressure (2nd principal stress) $\sigma_{2}$ and normal compressive stress $\sigma_{\theta}$ acting on a plane perpendicular to the $z-x$ plane. Dotted lines show the portions lacking data. 
gauge was in the $y-z$ plane for the gauge for $\sigma_{2}$, in the $z-x$ plane for the gauge for $\sigma_{\theta}$.

Principal stresses $\sigma_{1}$ and $\sigma_{3}$

Table 1 summarizes the results obtained by methods I ( $v$ assumed to be 0.15 ), II, and III, the last representing the hole-mark method. Because of lack of strain rate data in February, the results for two periods

TABLE 1. PRINCIPAL STRESSES $\sigma_{1}, \sigma_{3}$, plastic Poisson's ratio $v$ and viscosity $\eta$ obtained from three methods.

\begin{tabular}{|c|c|c|c|c|c|c|}
\hline Period & \multicolumn{6}{|l|}{$3 / 1$} \\
\hline Snow type & $\begin{array}{l}\text { compact } \\
\text { snow }\end{array}$ & & \multicolumn{2}{|c|}{$\begin{array}{l}\text { compact } \\
\text { snow }\end{array}$} & \multicolumn{2}{|c|}{$\begin{array}{c}\text { coarse-grained } \\
\text { snow }\end{array}$} \\
\hline Density $\left(\mathrm{kg} / \mathrm{m}^{3}\right)$ & 300 & & \multicolumn{2}{|c|}{300} & & 440 \\
\hline Snow temp. $\left({ }^{\circ} \mathrm{C}\right)$ & -2.9 & & \multicolumn{2}{|c|}{-0.9} & & 0 \\
\hline$\dot{\varepsilon},\left(.10^{-3} \mathrm{~d}^{-1}\right)$ & \multicolumn{3}{|c|}{2.08} & \multicolumn{2}{|c|}{-4.76} & \\
\hline$\dot{\varepsilon}_{3}\left(.10^{-3} d^{-1}\right)$ & \multirow{3}{*}{75} & -2.94 & & \multicolumn{2}{|c|}{-12.9} & \\
\hline (degree) & & & \multicolumn{2}{|c|}{71} & & 75 \\
\hline$\theta^{\prime} \quad$ (degree) & & \multicolumn{4}{|c|}{70.6} & 54 \\
\hline Method & I & II & III & I & II & III \\
\hline$(\mathrm{kPa})$ & 5.7 & 5.3 & 6.5 & -0.9 & -4.5 & 10.3 \\
\hline$(\mathrm{kPa})$ & -9.3 & -8.7 & -10.1 & -1.8 & -11.6 & -17.0 \\
\hline (kPa.d) & 1490 & 1390 & & 53 & 433 & \\
\hline v & & 0.16 & & & 0.03 & \\
\hline
\end{tabular}

in March are tabulated. Angle $\theta$ was directly obtained from the built-in clinometer, and $\theta$ ' (the angle on the last day in each period) was calculated from a rotation and strain ellipse, both having been obtained from the hole-mark method.

In the first half of March, $\sigma_{1}$ and $\sigma_{3}$ obtained from these three methods agreed with one another when snow was dry and compact with a density of $300 \mathrm{~kg} / \mathrm{m}^{3}$. Also viscosity $\eta$ and plastic Poisson's ratio $v$ obtained by method II almost agreed with the corresponding values obtained or assumed in the case of method I. Besides, $\theta$ was in accordance with $\theta$ ', which indicates that flow of the snow was hardly influenced by the gauge. During all the measurement periods, layer boundaries remained almost parallel. Moreover the accuracy of strain rate measurements was faily high except in the snow-melting season. Therefore $\sigma_{1}, \sigma_{3}$ determined by method III are very close to the real magnitudes in this period. These facts indicate that the relation between stress and strain rate, both averaged for about two weeks, in the snow cover on a slope is well expressed by Equation 1. Values of $v$ are short, for few measurements of it have been made. So method II is more favorable, for it needs no assumed values of $v$. Method I will be effective after dependence of $v$ on density and snow type is made clear.

In the second half of March, these methods gave fairly different magnitudes of $\sigma_{1}$ and $\sigma_{3}$. For this period snow became coarse-grained by melting, with a density ranging from 300 to $440 \mathrm{~kg} / \mathrm{m}^{3}$. In the snow-melting season the accuracy of strain is substantially lower since the region where a finite homogeneous strain takes place becomes considerably small. Therefore when snow is melting, principal stresses should be determined from three normal compressive stresses using Mohr's circle, without the strain rate.

\section{CONCLUSION}

On a slope, a lateral pressure parallel to the contour line (2nd principal stress), a normal compressive stress perpendicular to lateral pressure and its direction were calculated in a snow cover flowing down two-dimensionally, using thin circular snow pressure gauges each with a clinometer. In addition, a plastic Poisson's ratio was obtained by measuring both vertical pressure and horizontal pressure in snow cover on level ground. Principal stresses perpendicular to the lateral pressure, averaged for two weeks, were determined by two methods based on linear constitutive equations, using values obtained from the above measurements, principa strain rates and/or their directions, the latter two having been measured by the hole-mark method. These principal stresses were compared with those obtained by the hole-mark method.

As a result, linear constitutive equations produced consistent results for such an analysis along with estimates on $\boldsymbol{\eta}$ and $v$, except in the snow-melting season. Furthermore, plastic Poisson's ratio $v$ obtained on the level ground was 0.15 in the case of a dry and compact snow, with a density ranging from 280 to $380 \mathrm{~kg} / \mathrm{m}^{3}$ This value agreed well with the value $(v=0.16)$ calculated from a snow with a density of $300 \mathrm{~kg} / \mathrm{m}^{3}$ on a slope.

\section{ACKNOWLEDGEMENTS}

The authors thank members of the Snow Damage Section of the Institute of Low Temperature Science and of the Teshio Experimental Forest.

\section{REFERENCES}

de Quervain M R 1965 Measurements of the pressure at rest in a horizontal snow cover. International symposium on scientific aspects of snow and ice avalanches, Davos, IASH Publ. No 69: 154-159

Huzioka T, Shimizu H, Akitaya E, Narita H, Ooizumi M 1982 Strain rate and stresses of snow on a mountain slope, Toikanbetsu, northern Hokkaido. V. (1981-1982 winter). Low Temperature Science, A, 41 Data Report: $9-25$

Salm B 1967 An attempt to clarify triaxial creep mechanics of snow. In Oura $\mathrm{H}$ (ed) Physics of Snow and Ice. International Conference on Low Temperature Science 1966, Proceedings 1(2): 857-874

Shimizu H, Akitaya E, Oh'izumi M, Hirabayashi Y 1985 Measurements of strains and pressure in a snow cover on a slope. Annals of Glaciology 6:303-3 s)

Shimizu H, Huzioka T 1975 Internal strains and stresses of snow cover on slopes. Snow Mechanics, Proceedings of the Grindelwald Symposium 1974, IAHS - AISH Publ. No 114: 321-331

Yosida Z 1980 Studies of the behavior of a snow cover on a mountain slope VII. Single vertical principal stress. Low Temperature Science A 39: 1-16 